\title{
Kualitas Pelayanan terhadap Kepuasan Nasabah pada PT. Mandiri Tunas Finance
}

\author{
Reza Kurniawan ${ }^{凶}$ \\ Sekolah Tinggi Ilmu Ekonomi Purna Graha \\ DOI : https://doi.org/10.37531/ecotal.v1i1.2
}

\begin{abstract}
ABSTRAK
Penelitian ini dilakukan di PT. Mandiri Tunas Finance Cabang Pekanbaru. Tujuan penelitian ini adalah untuk mengetahui Pengaruh Kualitas Pelayanan terhadap Kepuasan Nasabah pada PT Mandiri Tunas Finance Cabang Pekanbaru. Populasi dalam penelitian ini adalah 2.390 pelanggan. Dalam penelitian ini pengambilan sampel menggunakan teknik Accidental Sampling yang berjumlah 96 pelanggan. Data yang digunakan adalah data primer dan sekunder dengan analisis menggunakan regresi linier sederhana. Hasil penelitian menunjukkan $Y=14,820+1,035$ dan uji t menunjukkan bahwa t hitung> dari t tabel $(18,471>1,98552)$ hal ini berarti Kualitas Pelayanan berpengaruh signifikan terhadap Kepuasan Pelanggan PT. Mandiri Tunas Finance Cabang Pekanbaru. Pengaruh Kualitas Pelayanan terhadap Kepuasan Pelanggan sebesar 78.4\% sedangkan sisanya $21.6 \%$ dipengaruhi oleh variabel lain.
\end{abstract}

Kata Kunci :

kepemimpinan, kompetensi, disiplin, dan kinerja

\begin{abstract}
This research was conducted at PT. Mandiri Tunas Finance Pekanbaru Branch. The purpose of this study was to determine the Effect of Service Quality on Customer Satisfaction at PT Mandiri Tunas Finance Pekanbaru Branch. The population in this study was 2,390 customers. In this study sampling using Accidental Sampling techniques, which amounted to 96 customers. The data used are primary and secondary data with analysis using simple linear regression. The results showed $Y=14.820+1.035$ and the $t$ test showed that $t$ arithmetic $>$ from $t$ table $(18,471>$ 1,98552) this meant that Quality of Service had a significant effect on Customer Satisfaction of PT. Mandiri Tunas Finance Pekanbaru Branch. The influence of Service Quality on Customer Satisfaction is $78.4 \%$ while the remaining $21.6 \%$ is influenced by other variables.
\end{abstract}

Keywords : leadership, competence, discipline, and performance

$\triangle$ Corresponding Author :

E-mail address: reza22@gmail.com (Kota Pekanbaru, Riau)

“Received 03 December 2019, Accepted 04 January 2020, Published 15 January 2020" 
Reza Kurniawan $^{凶}$

Kualitas Pelayanan terhadap Kepuasan Nasabah pada PT. Mandiri Tunas Finance

DOI : https://doi.org/10.37531/ecotal.v1i1.2

\section{Pendahuluan}

Era globalisasi persaingan bisnis menjadi semakin sangat tajam, baik di pasar domestik (nasional) maupun di pasar internasional. Perusahaan memerlukan strategi untuk menghadapi persaingan yang saat ini semakin lama semakin ketat. Terdapat berbagai tantangan dalam mencapai keberhasilan perusahaan. Untuk mengantisipasinya, perusahaan dituntut untuk dapat bekerja dengan baik dengan menggunakan berbagai macam sumber daya yang dimiliki agar dapat diterima di pasar. Salah satu yang perlu diperhatikan perusahaan dalam mencapai keberhasilan adalah kualitas pelayanan. Sehubungan dengan kontak personal yang sangat penting dalam menentukan kualitas pelayanan, setiap perusahaan memerlukan service excellence atau pelayanan unggul, yaitu suatu sikap/cara karyawan dalam melayani konsumen secara memuaskan (Rizqa Ramadhaning Tyas dan Ari Setiawan, 2012).

Pelayanan pada dasarnya adalah kegiatan yang ditawarkan oleh organisasi atau perorangan kepada konsumen, yang bersifat tidak berwujud dan tidak dapat dimiliki. Secara umum, pelayanan di Indonesia masih dinilai kurang baik dan dianggap bertele-tele sehingga masalah tersebutlah yang harus diperbaiki oleh perusahaan dan lembaga lainnya agar dapat merubah citra buruk tersebut menjadi lebih baik. Seperti yang kita ketahui, masalah adalah ketidaksesuaian suatu keadaan dengan apa yang diinginkan. Begitu juga halnya dalam dunia perbankan, perkembangan teknologi yang semakin maju membuat keunggulan suatu produk sulit untuk dipertahankan, karena pada dasarnya produk lebih mudah untuk ditiru. Untuk itulah, pelayanan yang baik dan berkualitas sangat diperlukan agar dapat memberikan pelayanan yang prima dan kualitas sesuai yang diinginkan serta diharapkan oleh para nasabahnya agar dapat membuat nasabah merasa puas.

Keberhasilan suatu perusahaan sangat dipengaruhi oleh kinerja individu karyawannya. Setiap perusahaan akan selalu berusaha untuk mendapatkan kinerja terbaik dari karyawannya, dengan harapan apa yang menjadi tujuan perusahaan akan tercapai. Perusahaan leasing memiliki peran yang cukup penting dalam pembiayaan barang-barang moda atau barang konsumtif.Jenis barang yang dibiayain pun terus meningkat. Jika sebelumnya hanya terfokus pada pembiayaan kendaraan bermotor, kini berkembang pada keperluan kantor, manufaktur, konstruksi dan pertanian. Hal ini mengindikasikan multi finance demikian dikenal dan diandalkan oleh pelaku usaha nasional. Kepuasan nasabah menjadi sangat penting bagi suatu perusahaan, yang dalam 
Reza Kurniawan $^{凶}$

Kualitas Pelayanan terhadap Kepuasan Nasabah pada PT. Mandiri Tunas Finance

DOI : $\underline{\text { https://doi.org/10.37531/ecotal.v1i1.2 }}$

penelitian ini adalah perusahaan yang bergerak di bidang jasa perbankan, di mana pelayanan yang baik memegang peran utama dalam memberikan kepuasan kepada para nasabahnya. Dengan pelayanan ini maka akan memunculkan suatu tingkat kepuasan pada nasabah baik itu kepuasan positif.

\section{Kajian Literatur}

\subsection{Pengertian Kualitas Pelayanan}

(Tjiptono, 2012:51) menyatakan bahwa kualitas pelayanan merupakan suatu kondisi dinamis yang berhubungan dengan produk, jasa, manusia, proses dan lingkungan yang memenuhi atau melebihi harapan. Sebuah perusahaan berpotensi meningkatkan pangsa pasar melalui pemenuhan tingkat kualitas pelayanan pelanggan. (Nilasari \& Istiatin, 2015). Usmara (2003) dalam Abdul Gofur (2019), bahwa kualitas pelayanan merupakan suatu pernyataan tentang sikap, hubungan yang dihasilkan dari perbandingan antara ekspektasi (harapan) dengan kinerja (hasil). Kepuasan dipengaruhi oleh perbandingan layanan yang dipahami dengan pelayanan yang diharapkan, dan sebagai reaksi emosional jangka pendek pelanggan terhadap kinerja pelayanan tertentu (Anita Librianty dan Rudi Triadi Yuliarto, 2019).

\subsubsection{Dimensi Kualitas Pelayanan}

(Kotler, 2012:284) menyebutkan lima dimensi kualitas pelayanan yang harus dipenuhi yaitu :

a). Bukti fisik (tangibles) yaitu penampilan fisik layanan perusahaan, seperti penampilan fasilitas fisik, peralatan, personel, kebersihan, kerapian dan media komunikasi. Bukti fisik merupakan kemampuan suatu perusahaan dalam menunjukkan eksistensinya kepada pihak eksternal (Arum Novitasari dan Nanik Suryani, 2004).

b). Kehandalan (reliability) yaitu kemampuan perusahaan untuk melaksanakan jasa yang dijanjikan dengan tepat dan terpercaya. Menurut Zeithmal dalam (Sirhan Fikri, 2016) kehandalan adalah kemampuan dan kehandalan untuk menyediakan pelayanan terpercaya, cepat dan tidak pilih kasih.

c). Daya tanggap (responsiveness) yaitu daya tanggap perusahaan dalam memberi layanan bagi pelanggan dan memberikan jasa dengan sigap dan cepat dalam melayani menangani transaksi dan penanganan keluhan pelanggan. Menurut Menurut Zeithaml dalam Umar dalam Hari Margono daya tanggap, yaitu respon atau kesigapan karyawan dalam membantu pelanggan dan memberikan pelayanan yang cepat dan tanggap, yang meliputi kesigapan karyawan dalam 
Reza Kurniawan $^{凶}$

Kualitas Pelayanan terhadap Kepuasan Nasabah pada PT. Mandiri Tunas Finance

DOI : https://doi.org/10.37531/ecotal.v1i1.2

melayani pelanggan, kecepatan karyawan dalam menangani transaksi, dan penanganan pelanggan keluhan pelanggan (Hari Margono, 2010)

d). Jaminan (assurance) yaitu kemampuan perusahaan memberi jaminan pelayanan yang merupakan pengetahuan dan kesopanan karyawan serta kemampuan mereka untuk menimbulkan kepercayaan dan keyakinan. Dalam (https://sinta.unud.ac.id/uploads/wisuda/0816051202-3-BAB\%20II\%20lisa.pdf) istilah jaminan merupakan terjemahan dari bahasa Belanda, yaitu zekerheid atau cautie. Zekerheid atau cautie mencakup secara umum cara-cara kreditur menjamin dipenuhinya tagihannya, disamping pertanggungan jawab umum debitur terhadap barang-barangnya.

e). Empati (emphaty) yaitu kesediaan karyawan dan pengusaha untuk lebih peduli memberikan perhatian secara pribadi kepada pelanggan. Menurut Zeithaml dan Bitner dalam (Marwanto, 2015:100) mengatakan bahwa kepuasan yang dirasakan oleh seorang pelanggan juga mempengaruhi oleh beberapa faktor seperti: kualitas pelayanan, kualitas produk, harga, faktor situasi, dan tentunya faktor pribadi dari pelanggan. kepuasan pelanggan adalah keadaan emosional, sebuah gambaran reaksi pasca pembelian, dapat berupa kemarahan, kegembiraan, atau kesenangan. Maka tidak heran banyak perusahaan yang sangat terobsesi dengan kepuasan pelanggan. Empati adalah kemampuan menempatkan diri kita pada diri orang lain, bahwa kita telah memahami bagaimana perasaan orang lain tersebut, dan apa yang menyebabkan reaksi mereka tanpa emosi kita terlarut dalam emosi orang lain (Damayanti dalam Faizah dkk, 2017).

\subsubsection{Indikator Kepuasan Nasabah}

(Aryani, Dwi, 2010:314) mengidentifikasi empat metode untuk mengukur kepuasan pelanggan : sistem keluhan dan saran, ghost shopping, lost costumer analysis, dan survei kepuasan pelanggan. Kepuasan nasabah akan menimbulkan loyalitas nasabah. (Simamora, 2007). Informasi ini dapat memberikan ide-ide dan masukan kepada perusahaan dan memungkinkan untuk bereaksi dengan tanggap dan cepat untuk mengatasi masalah (http://www.pendidikanekonomi.com/2012/07/pengertian-dan-pengukuran-kepuasan.html)

Metode Ghost Shoping ini merupakan suatu cara untuk melihat kinerja terutama sumber daya manusia dalam melaksanakan kegiatan pekerjaan dan pelayanan terhadap konsumen dalam hal ini kinerja penyedia pelayanan kesehatan terhadap klien/pasien (Annies Shafira \& Asmanadia Hidayat, 2013). 
Reza Kurniawan $^{凶}$

Kualitas Pelayanan terhadap Kepuasan Nasabah pada PT. Mandiri Tunas Finance

DOI : https://doi.org/10.37531/ecotal.v1i1.2

Sedapat mungkin perusahaan menghubungi para pelanggan yang telah berhenti membeli atau yang telah berpindah ke pemasok lain agar dapat memahami mengapa hal itu terjadi sehingga dapat mengambil kebijakan/penyempurnaan selanjutnya (Alvi Furwanti Alwie \& Deny Danar Rahayu, 2009). Pencapaian kepuasan dapat merupakan proses yang sederhana, maupun kompleks dan rumit,dalam hal ini peranan setiap individu dalam service enconter sangatlah penting dan berpengaruh terhadap kepuasan yang dibentuk (Dewi dkk, 2017). Kepuasan atau ketidakpuasan yang dihasilkan sangat besar pengaruhnya dalam membangun loyalitas pelanggan (Maskuri Sutomo, 2010). Kepuasaan pelanggan merupakan respon pelanggan terhadap perbandingan antara kinerja dan harapan sesuai dengan evaluasi ketidaksesuaian setelah pelanggan memakai suatu produk (http://repository.uma.ac.id/bitstream/123456789/493/5/118320021_file5.pdf)

\subsection{Pengaruh Kualitas Pelayanan Terhadap Kepuasan Nasabah}

(Rianto Zalukhu, 2014:102) sistem pelayanan yang baik perlu mengetahui dimensi kualitas pelayanan yang meliputi: Bukti fisik (tangibles), kehandalan (reliability), daya tanggap (responsiveness), jaminan (assurance), dan empati (emphaty). Sehingga dapat disimpulkan bahwa kualitas pelayanan suatu perusahaan merupakan salah satu faktor yang mempengaruhi kepuasaan nasabah dalam membeli suatu produk atau jasa yang ditawarkan atau dijual oleh sutau perusahaan. Kebersihan perusahaan dalam memberikan pelayanan yang lebih kepada nasabah akan membuat nasabah menjadi loyal dalam menggunakan produk yang ditawarkan secara berulang ulang. Dengan demikian dapat diketahui bahwa kualitas pelayanan mempunyai pengaruh terhadap kepuasan nasabah. Semakna dengan (Novia Susanti dan Arsyad Syahrian, 2019) bahwa kualitas adalah sebuah bentuk pengukuran terhadap suatu nilai layanan yang telah diterima oleh konsumen dan kondisi yang dinamis suatu produk atau jasa dalam memenuhi harapan pelanggan.

\section{Metode Penelitian}

Penelitian ini mengambil lokasi yang berada di PT Mandiri Tunas Finance Cabang Pekanbaru yang beralamat di jalan Arifin Ahmad komplek Bisnis Center No. 25-26 Pekanbaru. Jenis dan Sumber Data populasi penelitian ini adalah seluruh nasabah pada tahun 2019 yang berjumlah 2.390 nasabah. Sampel Menurut (Sugiyono, 2013: 116) "Sampel adalah bagian dari jumlah dan karakteristik yang dimiliki oleh populasi tersebut". Besarnya jumlah sampel dalam penelitian ini, 
maka peneliti menggunakan rumus Slovin untuk memperkecil jumlah populasi. Dengan demikian jumlah sampel adalah dibulatkan menjadi 96 nasabah. Untuk menentukan sampel yang akan digunakan dalam penelitian digunakan metode Sampling Accidental. Teknik Sampling Accidental dilakukan pemilihan anggota sampelnya terhadap orang atau benda yang kebetulan ada atau dijumpai dan dipandang orang yang dijumpai tersebut cocok dijadikan sumber data.

\section{Hasil dan Pembahasan}

\subsection{Deskripsi Penelitian}

Analisis secara deskriptif pada variabel Kualitas Pelayanan menunjukkan nilai rata-rata yang diperoleh sebesar 3,96. Hal ini menunjukkan Kualitas Pelayanan PT Mandiri Tunas Finance Cabang Pekanbaru sudah baik. Analisis secara deskriptif pada variabel Kepuasan Nasabah menunjukkan nilai rata-rata yang diperoleh sebesar 4,03. Hal ini menunjukkan Kepuasan Nasabah PT Mandiri Tunas Finance Cabang Pekanbaru sudah baik.

\subsection{Uji Regeresi Linier Sederhana}

Analisis yang digunakan umtuk melihat arah hubungan antara variabel bebas terhadap terikat, serta untuk melihat besaran perubahan peningkatan variabel terikat, akibat dari perubahan variabel bebas sebesar satu-satuan. Berikut adalah hasil output regresi linier sederhana.

Tabel 1. Regresi Linier Sederhana

\section{Coefficients $^{\mathrm{a}}$}

\begin{tabular}{|c|c|c|c|c|c|}
\hline \multirow[b]{2}{*}{ Model } & \multicolumn{2}{|l|}{$\begin{array}{c}\text { Unstandardized } \\
\text { Coefficients }\end{array}$} & \multirow{2}{*}{$\begin{array}{c}\begin{array}{c}\text { Standardized } \\
\text { Coefficients }\end{array} \\
\text { Beta } \\
\end{array}$} & \multirow[b]{2}{*}{$\mathrm{t}$} & \multirow[b]{2}{*}{ Sig. } \\
\hline & $\mathrm{B}$ & Std. Error & & & \\
\hline 1 (Constant) & 14.820 & 4.472 & & 3.314 & .001 \\
\hline Pelayanan & 1.035 & .056 & .885 & 18.471 & .000 \\
\hline
\end{tabular}

a. Dependent Variable : Kepuasan_Nasabah

Sumber: Data Olahan, 2020

Dari tabel 1 di atas dapat diperoleh persamaan regresi linear sederhana sebagai berikut: $Y=$ $14,820+1,035 X$. Persamaan ini dapat diartikan sebagai berikut: 
1. Konstanta sebesar 14,820 , artinya jika variabel bebas bernilai nol, maka kepuasan nasabah pada PT Mandiri Tunas Finance Cabang Pekanbaru sebesar 14,820.

2. Koefisien regresi variabel Kualitas Pelayanan sebesar 1,035 artinya jika variabel Kualitas Pelayanan bertambah, maka Kepuasan Nasabah pada PT Mandiri Tunas Finance Cabang Pekanbaru sebesar 1,035.

\subsection{Uji t}

Uji_t adalah uji statistik yang digunakan umtuk menguji hipotesis penelitian, yaitu apakah menerima hipotesis atau menolak. Yaitu dengan membandingkan antara nilai t_hitung dengan nilai t_tabel. Menentukan nilai t_tabel adalah dengan rumus: $n-2$, baris dan pada alfa 0,05/2, kolom, maka diperoleh: 96-2 = 94 (baris) dan alfa 0,05/2 (kolom), maka diperoleh nilai t_tabel yaitu 1,98552. Berdasarkan tabel 5.56 di atas terlihat bahwa nilai t hitung untuk variabel bebas memiliki nilai > dari nilai t_tabel $(1,98552)$, maka dapat disimpulkan bahwa variabel bebas memiliki pengaruh yang signifikan terhadap variabel terikat. Sedangkan variabel memiliki nilai t_hitung $(18,471)$ lebih besar > dari nilai t_tabel $(1,98552)$, maka dapat disimpulkan bahwa variabel bebas Kualitas Pelayanan berpengaruh signifikan terhadap Kepuasan Nasabah pada PT Mandiri Tunas Finance Cabang Pekanbaru.

\subsection{Koefisien Determinasi (R2)}

Koefisien determinasi adalah nilai koefisien yang digunakan untuk melihat seberapa besar pengaruh atau kontribusi variabel bebas terhadap varaibel terikat, yaitu semakin tinggi nilai Koefisien determinasi atau mendekati 1, maka semakin tinggi atau baik variabel terikat. Berikut adalah hasil Koefisien Determinasi:

Tabel 2. Nilai Koefisien Determinasi

\begin{tabular}{|c|c|c|c|c|}
\hline \multicolumn{5}{|c|}{ Model Summary ${ }^{b}$} \\
\hline Model & $\mathrm{R}$ & $\begin{array}{l}\mathrm{R} \\
\text { Square }\end{array}$ & $\begin{array}{l}\text { Adjusted R } \\
\text { Square }\end{array}$ & $\begin{array}{l}\text { Std. Error of the } \\
\text { Estimate }\end{array}$ \\
\hline 1 & $.885^{\mathrm{a}}$ & .784 & .782 & 463.367 \\
\hline
\end{tabular}

a. Predictors : (Constant), Kualitas_Pelayanan

b. Dependent Variable : Kepuasan_Nasabah

Sumber: Data Olahan, 2020 
Reza Kurniawan $^{凶}$

Kualitas Pelayanan terhadap Kepuasan Nasabah pada PT. Mandiri Tunas Finance

DOI : https://doi.org/10.37531/ecotal.v1i1.2

Berdasarkan tabel 2 di atas diperoleh angka R Square sebesar 0,784 atau menunjukkan bahwa $78,4 \%$ besarnya pengaruh variabel Kualitas Pelayanan terhadap Kepuasan Nasabah pada PT Mandiri Tunas Finance Cabang Pekanbaru. Sedangkan sisanya sebesar 21,6\% dipengaruhi oleh variabel lain yang tidak dimasukkan dalam penelitian ini atau bahwa variabel terikat mampu dijelaskan oleh variabel bebas, artinya model yang digunakan sudah selesai.

\section{Kesimpulan}

Berdasarkan hasil regresi sederhana diperoleh persamaan $Y=14,820+1,035$, yaitu memiliki arah hubungan positif antara variabel bebas terhadap variabel terikat. Variabel bebas memiliki pengaruh yang signifikan terhadap variabel terikat. Sedangkan variabel memiliki nilai t_hitung $(18,471)$ lebih besar > dari nilai t_tabel $(1,98552)$, maka dapat disimpulkan bahwa variabel bebas Kualitas Pelayanan berpengaruh signifikan terhadap Kepuasan Nasabah pada PT Mandiri Tunas Finance Cabang Pekanbaru. Diperoleh angka R Square sebesar 0,784 atau menunjukkan bahwa $78,4 \%$ besarnya pengaruh variabel Kualitas Pelayanan terhadap Kepuasan Nasabah pada PT Mandiri Tunas Finance Cabang Pekanbaru. Sedangkan sisanya sebesar 21,6\% dipengaruhi oleh variabel lain yang tidak dimasukkan dalam penelitian ini atau bahwa variabel terikat mampu dijelaskan oleh variabel bebas, artinya model yang digunakan sudah selesai.

\section{Referensi :}

Abdul Gofur. (2019). Pengaruh Kualitas Pelayanan dan Harga Terhadap Kepuasan Pelanggan. Jurnal Riset Manajemen dan Bisnis (JRMB) Fakultas Ekonomi UNIAT.

Alwie, Alvi Furwanti \& Deny Danar Rahayu. Analisis Kepuasan Pelanggan (Customer Satisfaction) terhadap Layanan Hypermart Pekanbaru. Jurnal Ekonomi, Volume 17, Nomor 2 Agustus 2009, h. 21-27.

Anita Librianty Rudi Triadi Yuliarto. Pengaruh Kualitas Pelayanan terhadap Kepuasan Pelanggan pada PT. PLN (Persero) Rayon Jawi Pontianak. Aset, Maret 2019, hal. 1-7, Vol. 21 No. 1.

Aryani, Dwi. (2010). Pengaruh Kualitas Pelayanan Terhadap Kepuasan Pelanggan Membentuk Loyalitas Pelanggan. Universitas Indonesia: Jakarta.

Dewi H.Chalil H.Syamsulbahri. (2017). Pengaruh Kualitas Layanan terhadap Kepuasan Nasabah pada PT. Mandala Multi Finance Cabang Palu. Vol. 3, No. 2, Mei 2017, 151-158.

Elisabeth R. Simamora. (2007). Analisis Faktor - Faktor Yang Membangun Kepuasan Nasabah Untuk Meningkatkan Loyalitas Pelanggan (Studi Empiris Nasabah PT. Bank Tabungan Negara Cabang Semarang). Universitas Diponegoro: Semarang.

Eswika Nilasari \& Istiatin. (2015). Pengaruh Kualitas Pelayanan terhadap Kepuasan Konsumen pada Dealer PT. RA. Jurnal Paradigma Vol. 13, No. 01. 
Faizah, dkk. Empati terhadap Siswa Berkebutuhan Khusus: Ditinjau dari Jenjang Pendidikan Inklusi dan Jenis Kelamin. DOI: 10.14710/jpu.16.1.1-7.

Fikri, Sirhan dkk. Pengaruh Kualitas Pelayanan Terhadap Kepuasan dan Loyalitas Mahasiswa (Studi pada Mahasiswa Strata I Fakultas Ilmu Sosial dan Ilmu Politik Universitas Merdeka Malang). Jurnal Bisnis dan Manajemen Vol. 3 No.1, Januari 2016, h. 120134.

https://sinta.unud.ac.id/uploads/wisuda/0816051202-3-BAB\%20II\%20lisa.pdf http://repository.uma.ac.id/bitstream/123456789/493/5/118320021_file5.pdf

http://www.pendidikanekonomi.com/2012/07/pengertian-dan-pengukuran-kepuasan.html

Margono, Hari. Hubungan Antara Bukti Fisik, Keandalan, Daya Tanggap, Jaminan dan Empati dengan Tingkat Kepuasan Pemakai Jasa Perpustakaan Universitas Sanata Dharma Kampus I Mrican Studi pada Mahasiswa Universitas Sanata Dharma Yogyakarta Pemakai Jasa Perpustakaan Kampus I Mrican. YOGYAKARTA, 2010.

Novitasari, Arum \& Nanik Suryani. Pengaruh Bukti Fisik, Keandalan, Daya Tanggap, Jaminan, dan Empati terhadap Kepuasan Pengguna Jasa UPT Perpustakaan Universitas Negeri Semarang. Economic Education Analysis Journal, 3 (2) (2014), p. 275-282.

Novia Susanti \& Arsyad Syahrian. (2014). Analisis Pengaruh Kualitas Pelayanan pada Kepuasan dan Loyalitas Pelanggan di Salon dan SPA.

Rianto Zalukhu, Roni. (2014). Metodologi Riset Bisnis. Al-Huda Press:Pekanbaru.

Rizqa Ramadhaning Tyas dan Ari Setiawan. (2012). Pengaruh Lokasi dan Kualitas Pelayanan terhadap Keputusan Nasabah untuk Menabung di BMT Sumber Mulia Tuntang. Volume 3 Nomor 2, Desember.

Shafira, Annies \& Asmanadia Hidayat. Laporan Praktik Belajar Lapangan Ghost Shopping Indeks Kepuasan Masyarakat di Rumah Sakit Advent Kota Bandung. Bandung, 2013.

Sugiyono. (2010). Metode Penelitian Kuantitatif Kualitatif dan R\&D. Alfabeta: Bandung.

Sutomo, Maskuri. Kepuasan Pelanggan Menginap pada Hotel Berbintang di Daerah Istimewa Yogyakarta (Survey Pelanggan pada Hotel Bintang Tiga, Empat dan Lima Di Daerah Istimewa Yogyakarta). Strategic, Volume 9, Nomor 17, Februari 2010, 53-75. 